\title{
A Sector Wheel Approach to Understanding the Needs and Barriers to Services among Homeless- Experienced Veteran Families
}

\author{
Roya Ijadi-Maghsoodi, MD, MSHPM, Sophie Feller, MD, Gery W. Ryan, PhD, \\ Lisa Altman, MD, Donna L. Washington, MD, MPH, Sheryl Kataoka, MD, MSHS, and \\ Lillian Gelberg, MD, MSPH
}

Background: Veteran family homelessness is a significant issue, yet little is known about the needs and barriers to services of veteran families experiencing homelessness. This qualitative study examined the experiences, needs, and barriers to services among homeless-experienced veteran families to inform providers for this important population.

Methods: Twenty-five semi-structured interviews were conducted from February through September 2016 with 18 veteran parents with a recent history of homelessness ( 9 mothers, 9 fathers), and 7 homeless service providers throughout Los Angeles County. The "Sector Wheel for Under-Resourced Populations" data elicitation approach was used to conduct the interviews, which allowed the participant to guide the interview by discussing different sectors of a family's life affected by homelessness. The interviews were audio-recorded, transcribed, and themes were coded with Atlas.ti.

Results: Interviews revealed parenting stress and worsening family mental health during homelessness. Participants described barriers to navigating housing, social, and health services with children, including not knowing where to seek help, difficulty connecting to health and social services in the community, and a lack of family-focused services. Parents encountered discrimination by landlords and lack of access to permanent housing in safe neighborhoods.

Conclusions: Findings demonstrate a need for delivering family-centered and comprehensive services to homeless-experienced veteran families that recognize the multifaceted needs of this population. Advocacy initiatives are needed to address discrimination against veterans experiencing family homelessness and increase access to affordable permanent housing in safe neighborhoods for families. (J Am Board Fam Med 2021;34:309-319.)

Keywords: Homeless Persons, Housing, Los Angeles, Mental Health, Military Medicine, Primary Health Care, Qualitative Research, Social Determinants of Health, Veterans Health

Veteran homelessness remains a critical issue in the United States (US). The 2019 point-in-time

Submitted 30 June 2020; revised 6 November 2020; accepted 9 November 2020.

From the VA Health Service Research \& Development (HSR\&D) Center for the Study of Healthcare Innovation, Implementation \& Policy (CSHIIP), VA Greater Los Angeles Healthcare System, Los Angeles, CA (RI-M, LG); UCLA Division of Population Behavioral Health, Semel Institute for Neuroscience \& Human Behavior, Los Angeles, CA (RI-M, SK); Department of Psychiatry and Biobehavioral Sciences, UCLA, Los Angeles, CA (RI-M, SF, SK); Department of Health Systems Science, Kaiser Permanente Bernard J. Tyson School of Medicine, Pasadena, California (GWR); Office of Healthcare Transformation and Innovation, VA Greater Los Angeles Healthcare System, Los Angeles, CA (LA, LG); Department of Medicine, David Geffen School of Medicine at UCLA (LA, DLW); UCLA Center for Health Services and Society, UCLA Semel Institute for Neuroscience and Human estimate found that over 37,085 veterans were experiencing homelessness on a given night. ${ }^{1}$ Further, 1 subgroup of homeless veterans-veterans with

Behavior, Los Angeles, CA (SK); Department of Family Medicine, David Geffen School of Medicine at UCLA, Los Angeles, CA (LG); and Department of Health Policy and Management, UCLA Fielding School of Public Health, Los Angeles, CA (LG)

Funding: Dr. Ijadi-Maghsoodi was supported by the VA Office of Academic Affiliations through the VA Advanced Fellowship in Women's Health during this work. Dr. IjadiMaghsoodi receives funding from the National Institute on Drug Abuse of the National Institutes of Health under Award Number K12DA000357, and the Greater Los Angeles VA UCLA Center of Excellence for Veteran Resilience and Recovery. At the time of this work, Dr. Sheryl Kataoka received funding from SAMHSA TSA Center for Resiliency, Hope, and Wellness in Schools, NIH Clinical and Translational Science, the Department of Education, DHHS/ 
children-remains under-researched. Little is known about the health, mental health, and social needs of veteran families during homelessness and after receiving housing (hereafter referred to as "homeless-experienced"), and how services can best meet these needs.

Veterans with children make up a considerable component of the homeless veteran population, especially among female veterans. Tsai and colleagues found that $9 \%$ of male veterans experiencing homelessness and 18\% who were unstably housed (at imminent risk of losing housing) had children in their custody, while these numbers are $30 \%$ and $45 \%$ respectively for female veterans. ${ }^{2}$

Compared with civilian families, veteran families have additional experiences, stressors, and risk factors that might place them at heightened risk of homelessness and challenges with homelessness. ${ }^{3-5}$ This includes military-related experiences such as parental deployment, reintegration stress after deployment, and the effect of parental combatrelated post-traumatic stress disorder (PTSD), or military sexual trauma (MST), on the family. ${ }^{6-8}$ Given these known challenges among housed veteran families, it is crucial to better understand the potential unique needs and stressors of homelessexperienced veteran families to tailor care for this population.

Yet, despite the indications that homeless-experienced veteran families are a distinct subset of the homeless population, a review of the literature demonstrates only 2 studies focused on homelessexperienced veteran families. ${ }^{2,9}$ In addition to the before-mentioned study by Tsai and colleagues, ${ }^{2}$ a second study explored the characteristics of homeless veteran parents in residential treatment programs. ${ }^{9}$ Findings showed that $38 \%$ of homeless veterans receiving residential services had children, but only $11 \%$ had children residing with them in the residential programs, with female veterans more likely to have children involved in the

Health Resources and Services Administration, and was a consultant for the Los Angeles Unified School District.

Conflict of interest: The other authors have no conflicts of interest to disclose.

Disclosures: This work was supported by a locally initiated project award from the HSR\&D Center for the Study of Healthcare Innovation, Implementation \& Policy at the Greater Los Angeles Healthcare System and a Greater Los Angeles Veteran Affairs Research Enhancement Award Program (REAP).

Corresponding author: Roya Ijadi-Maghsoodi, MD, MSHPM, 760 Westwood Plaza, Los Angeles, CA 90095 (E-mail: Rijadimaghsoodi@mednet.ucla.edu). programs. ${ }^{9}$ Although both studies highlighted the prevalence of veteran family homelessness, they did not explore the unique needs of these families.

Studies examining the experiences and needs of homeless veterans-including women-although informative, have not included the perspectives of veteran parents or specifically concentrated on veterans with families. ${ }^{4,10}$ For example, Hamilton and colleagues found that homeless women veterans experienced similar childhood adversity to homeless civilian women, yet also experienced military trauma and postmilitary mental health challenges related to military service, which the authors conceptualized as additional pathways to homelessness. ${ }^{3}$ Although this study highlights the unique experiences of veterans that can contribute to homelessness, it did not focus on veteran mothers.

Further, although research on nonveteran homeless families shows an increased risk of parental mental health issues and poor child health, mental health, and social outcomes, these studies have not concentrated on veteran families. ${ }^{1-14}$ Homelessness experts have called for more studies addressing the unique needs of veteran families experiencing homelessness to better serve this population., ${ }^{2,9}$

Given the initiative to house veterans through programs such as the Department of Veteran Affairs (VA) homeless service programs, the US Department of Housing and Urban DevelopmentVA Supportive Housing Programs (HUD-VASH), and Supportive Services for Veteran Families (SSVF), ${ }^{1,15,16}$ it is critical to better understand the experiences of homeless-experienced veteran families to inform care for veteran families in both the community and $\mathrm{VA}^{10,17}$ Our purpose was to describe the needs of homeless-experienced veteran families living in transitional or permanent housing, to inform primary care, mental health and social service providers. We conducted qualitative interviews with homeless-experienced veteran parents (homeless within the past 2 years) and homeless service providers in Los Angeles County (LAC), which has the nation's highest concentration of homeless veterans. ${ }^{18}$

\section{Methods \\ Participants}

We conducted 25 semi-structured interviews with a diverse sample of 18 homeless-experienced veteran parents and 7 homeless service providers from 
February through September 2016. Parents were recruited via flyers, letters, and staff referrals from 1 transitional housing facility, 1 transitional and permanent supportive housing organization, 1 permanent supportive housing facility, and an interprofessional primary care homeless clinic for veterans, all in Southern California. Transitional housing facilities provide temporary housing and case management, and permanent supportive housing facilities provide long-term housing and supportive services. ${ }^{19}$ Parents were eligible to participate if they had the following criteria: (1) a history of homelessness within 2 years, (2) were 18+ years old, (3) were VA health care eligible, and (4) had a child or youth in their custody. Providers were recruited through staff referrals from 4 transitional and/or permanent housing facilities in the community known for serving homeless-experienced veteran families, including facilities that parents were recruited from. We selected these sites given that homeless service providers work closely with homeless-experienced veteran families, often for months. Providers of homeless services were eligible if they provided services to homeless-experienced veteran families. The roles of the homeless service providers included providing case management, supportive services, and clinical programming at the housing facilities. Given that families often do not disclose homelessness, we purposefully sampled veteran parents and providers from sites known to serve homeless-experienced veteran families. No parents or providers declined to be interviewed and all met eligibility criteria. We were limited to collecting data from 9 fathers and 9 mothers by the Paperwork Reduction Actdesigned to minimize federal data collection without additional permissions. ${ }^{20}$ By the time of reaching our target enrollment we had reached thematic saturation in the interviews. ${ }^{21}$

\section{Interview Procedures}

To guide the interviews and ensure that we discussed a wide range of concerns with participants, researchers developed a "Sector Wheel for UnderResourced Populations," a data elicitation tool, consisting of 8 sectors of a family's life affected by homelessness (health and mental health, children, transportation, shelter, food, safety, income, and relationships) arranged around a wheel (Figure 1). The sectors were selected in discussion with community partners, including homeless-experienced parents and homeless service providers, about the sectors most important to homeless-experienced
Figure 1. Sector Wheel for Under-Resourced Populations. This was used as a data elicitation tool to ensure that participants could share a wide range of concerns about sectors of a family's life affected by homelessness while allowing the participant to take control over the interview. The tool was developed with input from parents with a history of homelessness and homeless service providers. During the interview, the participant moved the arrow on the Sector Wheel, selecting the order of sectors to discuss based on comfort and preference. All sectors were covered in the interview. The Sector Wheel was used from February to September 2016 during the interviews with parents and providers.



families. Bronfenbrenner's ecological model informed the development of the sector wheel and the interview guide. ${ }^{22}$ The wheel was developed to achieve the following goals: (1) the participant could take control over and guide the interview by spinning an arrow on the wheel to select the preferred sector order to discuss based on comfort and importance, and (2) to ensure that comprehensive information was obtained for each sector. The tool was designed to be participant-centric-thus the participant chose where to start the interview, spun the arrow choosing where to land, and chose what sector to cover next. Although the participant determined the order, the interviewer ensured that all sectors on the wheel were covered. For each sector, the participant was asked questions related to the following topics: (1) the overall experience of being a mother or father when homeless; (2) the experiences, and barriers/facilitators within each 
sector, and (3) recommendations for improving care and services. Providers were administered the same guide but asked about working with homeless-experienced veteran families.

A trained researcher-a child and adult psychiatrist experienced in providing care to homelessexperienced veterans and a health services researcher (RIM)—obtained verbal consent from participants before the interview. Interviews lasted 60 minutes. Participation was voluntary. Following the interview, a brief demographic survey was administered to each parent. Parents received \$25 as a voucher to exchange for cash at the local VA facility; providers did not receive financial incentives. Interviews were audio-recorded and transcribed by a third-party; transcripts were checked for accuracy. The Institutional Review Board (IRB) reviewed all materials and formally designated this project as a quality improvement activity.

\section{Data Analysis}

We used a 2-step approach to explore topics in the interviews. First, 2 research team members trained in qualitative analysis (RIM and SF) reviewed the transcripts independently to identify preliminary cross-sector topics relating to families and as suggested by the interview guide (eg, experiences of homelessness, barriers to services), then met to discuss the topics. Through iterative discussions with the rest of the team, we developed a codebookwhich was informed by Bronfenbrenner's ecological model. $^{22}$ The initial 2 research team members (RIM and SF) then coded the transcripts together using the codebook, to protect against interpreter bias. ${ }^{23}$ We constantly modified the codebook, collapsing, eliminating, and combining codes as we moved through the text. We used the general rule of if in doubt about text, to include the text in the coding, and then discuss the text. Any questions about the text were discussed as a team and any discrepancies in coding were iteratively discussed and resolved so that we were in complete agreement at the end of coding. We used qualitative data analysis software Atlas ti. 7.1 (Berlin, Germany $)^{24}$ to manage and code the transcripts. Using the constant comparison method, we looked for similarities and differences across the multiple sectors. ${ }^{25}$ In cases that were ubiquitous across multiple sectors, we combined topics to make larger thematic categories.
Table 1. Demographic Characteristics of Veteran Parent Participants Interviewed from February to September $2016(\mathrm{n}=18)$

\begin{tabular}{ll}
\hline & $\%$ \\
\hline Sex & 50 \\
Male & 50 \\
Female & \\
Race/ethnicity & 17 \\
Non-Hispanic Black & 39 \\
Hispanic/Latino/any race & 28 \\
Non-Hispanic White & 11 \\
Two or more races/non-Hispanic & 6 \\
Unknown & \\
Age, years & 40 (25 to 56) \\
Mean (range) & $1.6(1$ to 4$)$ \\
Average number of children/youth in custody & \\
Mean (range) & 28 \\
Marital status & 44 \\
Single & 28 \\
Married/living with significant other & \\
Divorced & 50 \\
Housing status & 50 \\
Transitional housing facility & \\
Permanent housing & \\
\hline
\end{tabular}

\section{Results}

Demographic characteristics of the 18 veteran parents are described in Table 1. No parents were married to each other.

Throughout the interviews, parents described their experiences within each sector through the context of having a family, or their household. In this article, we report on 3 meta themes that arose across the sectors focusing on the household experiences: (1) household stress; (2) housing stability; and (3) barriers to services. There was concordance in the cross-sectoral themes expressed by the parents and providers, and we did not find significant differences in the themes among parents currently living in transitional housing and those recently housed in permanent housing. We explore the themes primarily using quotes from parents with support from provider quotes, with examples from the different sectors.

\section{Housebold Stress}

Interviews revealed that parents felt the stress of homelessness reverberated across the household. Parents described this resulted in worsening 
parental anxiety and interpersonal tension, and family mental health.

\section{Parental Stress}

Parents described a powerful sense of family responsibility and identified with being a veteran. Yet they grappled with multiple roles and demands (ie, being a veteran, provider for the family, and a student). A father of a toddler described, "As a dad...stressful is an understatement. But powerless and bopeless are more like the strongest 2 (Parent \#7)." Despite working, collaborating with eviction defense, and calling homeless agencies for help, this father had still lost his housing.

Parents detailed a lack of time to parent when attending to multiple tasks. One father described, "You are just ticking away-work, market, laundry, car needs...I found myself taking care of everything. But...after a conversation with 1 of my kids, 'Did I answer your question?' Did I pay attention to them? And I found myself sometimes saying 'no' (Parent \#1)." Other parents described the strain of homelessness on their relationships, including partner conflict. One father explained how the stress of homelessness shattered his relationship with this wife, "....all I want to do is just fix that 1 problem [relationship with bis wife]. . And that major problem is not getting fixed... And it is hard for me to care about anything because that is the 1 thing I care about. Relationship with my wife and my daughter are the 2 most precious things I have that I cannot pay my way out (Parent \# 7)."

\section{Parent Health, Mental Health, and Substance Use}

When discussing health, most parents focused on discussing mental health problems, including experiencing worsened depression and PTSD. One mother of an adolescent son who had only very recently obtained housing described feeling she had hit rock bottom, "Being right here in this situation makes me feel like I'm at the bottom and I do not see my way up (Parent \#6)." Parents reported that PTSD symptoms were amplified during homelessness, although more salient among mothers; 5 of the mothers reported a history of MST, childhood, or combat trauma. One mother pointed out the lack of services for women who had experienced MST and were being further victimized when homeless, "Girls with MST need to get to the front of the line because we're out here being victimized... (Parent \#16)." Parents brought up using substances to cope;
1 father relapsed on opioids under the "brutal" stress of homelessness. He later stabilized through a VA methadone program.

Most parents described access to VA medical services and cited far fewer health concerns. However, 2 parents detailed severe health problems related to homelessness. One father described gaining 25 pounds as a result of living in his car with his son, while a mother described multiple medical morbidities and the need for frequent VA medical appointments-requiring her to find permanent housing close to the VA.

\section{Child Health and Mental Health}

Two-thirds of the parents described that their children's mental health-including attention and behavior-worsened during homelessness. Parents worried about the effects of their PTSD on their children. One mother who received PTSD treatment herself, but had not received resources for her family, voiced, "I know my kids also have the residuals of that [parental PTSD] because me and their father served.... I see that they are trying to help every veteran, but I got kids and they [VA] cannot help (Parent \#14)." A provider echoed concern about parental PTSD, "A lot of our parents have PTSD. I saw that firsthand with 2 children...who could not keep it together when I visited. . And the mother is literally falling apart because of her MST... (Provider \#3)."

Although children tended to be healthy and parents focused more on mental health problems, participants still described lapses in child medical care coverage, trouble accessing medications, and difficulties enrolling in services for developmental disorders such as autism.

\section{Housing Stability}

Many parents and providers reported a "housingfirst" theme-that permanent housing was essential before they could address other sectors. For example, 1 father-who had doubled up with another family before obtaining housing - did not want to enroll his children in school temporarily until they could find a consistent place to live: "There' s no consistency in your life when you are homeless...housing is the number 1 thing, getting somebody a place to live, then they can connect with the resources in their area (Parent \#3)." Several parents described not being able to obtain full custody of their children without permanent housing. A father, who had been living on the 
streets, detailed the anguish of needing permanent housing before gaining custody of his daughter: "...I had to go to court and there was going to be a custody thing for my daughter ... and that changed my whole way of thinking... I got to find a bome so I can have my daughter and take care of her (Parent \#13)."

For employment, although parents felt the VA and community programs helped with obtaining jobs and training — some deemed these efforts futile without a permanent address. One mother stated, "...And they are offering jobs and baircuts and resumes.... Are you kidding?! Where am I going to sleep tonight? (Parent \#16)" This parent also described difficulty addressing her mental health without a place to stay, "Trying to talk to a mental bealth professional after sleeping in my car..., my brain was spinning. I could not even process a lot of the info (Parent \#16)." A provider summed up the need for housing stability, "You make sure that you keep that roof over your head by all means necessary (Provider \#6).”

\section{Barriers to Services}

Parents and providers described difficulty navigating medical, mental health, and social services with families. Three barriers emerged as subthemes: (1) complexity and lack of coordination; (2) lack of family-focused services; and (3) children as a restriction.

\section{Complexity and Lack of Coordination}

Parents described not knowing where to ask for help for their family for exiting homelessness and felt they were navigating a "maze." Some reached out for help and received outdated shelter phone numbers or addresses. One parent felt hopeless by the process of obtaining help for homelessness at the VA, "I went through a lot of leaving messages, never calling back. ... there's no really 1 single area or just point of contact to get information...(Parent \#15)." However, many parents described receiving helpful housing and medical services at the VA themselves, yet had difficulty enrolling their family in community means-tested aid programs or obtaining community resources-such as lists of community food pantries-for their children. Several parents did not have their children enrolled in Medicaid or Supplemental Nutrition Assistant Programs (SNAP), describing reasons such as they did not know how to obtain the services or did not qualify. One mother asked for more support obtaining services, “...They should probably have... more information in reference to our children. . where is your point person to tell you, okay, this is how we can help you... (Parent \#14)." Some providers described a need to better coordinate services between the community and the VA. For example, 1 provider explained the difficulty of determining if her clients were VA health care eligible, and the need to quickly connect women to VA mental health services.

\section{Lack of Family-Focused Services}

Parents highlighted a need and desire for family services beyond housing - including health, mental health, and parenting support for families experiencing homelessness. A father relayed: “...There's no family bealth as far as through the VA. There's no counseling. . . There's no child stuff... That is something that should definitely open up for families at the VA because that is intertwined with the veterans' issues (Parent \#3)." Although parents felt their primary care and mental health needs were adequately supported through the VA, they described difficulty connecting to community services for family members during the crisis of homelessness. One father accompanied his wife to a community mental health clinic due to her worsening depression but described she felt stigmatized after standing in line outside for an hour with people passing by. A mother described a need for family services, "Where can I get my kid's mental health?. . He [son] came bome from school with the eye doctor saying that he needed glasses. How do I get him eyeglasses? My other kid needs braces...I know that they haven't seen a dentist yet (Parent \#14)."

Providers described a need for VA services to expand to the families of veterans experiencing homelessness. One provider described that the job of VA homeless services providers was to check on the veteran parent, rather than the family members, yet felt this was a missed opportunity to provide linkages to care for the whole family.

\section{Children as a Restriction}

An overarching theme throughout the interviews was that parents often were limited in accessing services and housing by having children. For example, 1 father could not bring his son with special needs on the VA shuttle that went to the housing authority.

Having children posed a barrier at housing facilities-leading to family separation. One mother was 
accepted to a shelter, but they would not take her baby. A provider at a family housing program described how families were forced to separate, "...the children have to be under the age of 12 and there can only be 2 [children].... I had a call the other day from 1 that had 5 and then you have to choose which ones you are going to bring (Provider \#7)."

When searching for permanent housing, parents were limited to finding housing that was safe for children. Parents described experiencing landlord discrimination against HUD-VASH voucher holders and a lack of units that took vouchers in safe locations with good schools and suitable for their children: “... There's no housing and nobody is willing to accept it. And the people that are willing to accept it... They are dangerous neighborhoods (Parent \#10)." Providers described a need to build landlord relationships and advocate for affordable housing in safe neighborhoods.

\section{Discussion}

To our knowledge, this is the first effort to highlight the lived experiences, stressors, and barriers to services among homeless-experienced veteran families living in transitional and permanent supportive housing. Although our findings only focus on families engaged with housing resources and cannot be generalized to all homeless-experienced veteran families, we found that parents were overwhelmed by parenting stressors, compounded by housing insecurity. Our findings, in part, are supported by literature on homeless-experienced civilian families, which show worsening parent mental health, and a diminished sense among fathers of guiding 1's children when experiencing homelessness. ${ }^{11,26}$ However our findings also demonstrate the unique issues that veteran parents grappled with, such as concern about the impact of their PTSD and MST on their children, and the distinct barriers trying to coordinate services between the VA and the community for their family members.

There are successful housing programs for veteran families including SSVF, which provides community outreach, rapid-rehousing, assistance with benefits, and homelessness prevention. ${ }^{27}$ Although these programs are invaluable in addressing veteran family homelessness, concerns raised by parents and providers point to the need for family services beyond housing, including addressing parenting, child health and mental health, linkage to the community, and support navigating services with children. Positive family relationships can improve the use of services among veterans, while poor family functioning can worsen the health and functioning of veterans. ${ }^{28-30}$ Veterans experiencing homelessness are already at increased risks of poor health and suicide. ${ }^{31-33}$ As participants voiced, addressing the comprehensive needs of the whole family can strengthen the care of veteran parents.

One way to address the needs of veteran families experiencing homelessness is to use a family-centered care (FCC) approach, which is a partnership between the family and the health system with sensitivity to family needs, recognized by the Institute of Medicine (IOM) and utilized with military families. ${ }^{34,35}$ One approach is training service providers experienced caring for single homeless adults (eg, case managers in the community or social workers in the HUD-VASH programs) on the challenges of homeless-experienced families. Service providers can provide increased linkage to community services (ie, Medicaid, SNAP), and medical and mental health referrals for nonveteran family members.

Another family-centered approach includes offering family therapy and parenting programs tailored for homeless-experienced families. Although family participation is a national priority of the $\mathrm{VA},{ }^{36,37}$ most mental health programs focus on couples rather than families and are not tailored to address family homelessness stressors. ${ }^{38}$ Information about family-based programs needs to be disseminated more readily to veterans experiencing homelessness and programs adapted for this population. ${ }^{39}$

Primary care providers in the communityincluding family medicine physicians who already take longitudinal and family approaches to patients-are well suited to address the comprehensive health and social needs of veteran families, including parents and children, at visits. ${ }^{40-42}$ Research demonstrates increased receipt of community resources, including parent employment, after screening for social risk factors at primary care visits. ${ }^{43}$ Findings from VA patient-centered medical homes for homeless veterans showed that incorporating social determinants of health into primary care led to reduced use of acute care. ${ }^{44}$ Community health centers, particularly the federal Health Care for the Homeless Program (HCHP)—Federally Qualified Health Centers (FQHCs) which cover a range of health, 
behavioral health, and social needs for adults and children, are uniquely positioned to address the intersecting social and health care needs of veteran families experiencing homelessness. ${ }^{45}$ Indeed, there are calls for homeless service organizations to form collaborative relationships with FQHCs to address health needs, with existing models that provide on-site clinics and visits to families. $^{46,47}$

When working with veterans who are homeless and parents, providers can inquire about family needs, parenting stress, and offer referrals for family therapy, parenting programs, mental health, and social services. Although further implementation research is needed, the Sector Wheel (Figure 1) could be utilized by primary care, mental health care, and social services as a patient empowered approach to the care of homeless-experienced veteran parents, to identify their priorities for addressing unmet health and social determinant of health needs.

Finally, the housing needs of homeless-experienced veteran families must be recognized with coordinated policy efforts. Despite having housing vouchers, parents were unable to find affordable housing in safe areas with good schools. ${ }^{16}$ This echoes struggles throughout the US, with affordable housing units clustered in high-poverty, low-opportunity neighborhoods. ${ }^{48,49}$ Families also encountered stigma based on veteran status and having a voucher when searching for housing. VA and HUD-VASH social workers should continue building landlord relationships in safe communities and decrease the stigma of housing veteran families with vouchers. Cities should incentivize developers to include affordable rental units in housing developments in high-opportunity areas. Some localities are prohibiting landlords from denying applicants housing because of voucher use. ${ }^{50}$ Providers working with veteran parents experiencing homelessness can recognize the stressors of finding safe housing for children and advocate for permanent housing in high-opportunity and safe areas.

There are limitations to our study. Interviews were conducted in a metropolitan area with robust homelessness resources. Parents were involved with VA services and living in transitional housing or permanent housing, thus may not represent the views of homeless veteran families not connected to VA resources or housing. Interviews were conducted with nonhealthcare homeless service providers working closely with families in housing settings, instead of primary care physicians. Future studies should elicit the perspectives of primary care physicians, including medical directors of community health centers, working closely with this population. Despite these limitations, our findings contribute to the literature given the paucity of studies, especially qualitative studies, with homeless-experienced veteran families.

\section{Conclusion}

Veterans with families experiencing homelessness described worsened mental health and stressors, and service barriers related to having children. Interviews demonstrated a need for providing comprehensive, family-centered services to veteran families to meet their unique needs.

The content and views expressed in this article are those of the authors and do not necessarily reflect the position or policy of the US Department of Veterans Affairs, the National Institutes of Health, or the United States Government. We would like to thank all of the parents and providers who shared their valuable insights and time.

To see this article online, please go to: http://jabfm.org/content/ 34/2/309.full.

\section{References}

1. Henry M, Watt R, Mahathey A, Ouellette J, Sitler A. The 2019 Annual Homeless Assessment Report (AHAR) to Congress. U.S. Department of Housing and Urban Development; 2020. Available at: https://files.hudexchange.info/resources/documents/ 2019-AHAR-Part-1.pdf. Accessed June 26, 2020.

2. Tsai J, Rosenheck RA, Kasprow WJ, Kane V. Characteristics and use of services among literally homeless and unstably housed US veterans with custody of minor children. Psychiatr Serv 2015;66: 1083-90.

3. Hamilton AB, Poza I, Washington DL. "Homelessness and trauma go hand-in-hand": Pathways to homelessness among women veterans. Womens Health Issues 2011;21:S203-S209.

4. Washington DL, Yano EM, McGuire J, Hines V, Lee M, Gelberg L. Risk factors for homelessness among women veterans. J Health Care Poor Underserved 2010;21:82-91.

5. Decker SE, Rosenheck RA, Tsai J, Hoff R, HarpazRotem I. Harpaz-Rotem I. Military sexual assault and homeless women veterans: clinical correlates and treatment preferences. Womens Health Issues 2013;23:e373-e380. 
6. Lester P, Peterson K, Reeves J, et al. The long war and parental combat deployment: effects on military children and at-home spouses. J Am Acad Child Adolesc Psychiatry 2010;49:310-20.

7. Freytes IM, LeLaurin JH, Zickmund SL, Resende RD, Uphold CR. Exploring the post-deployment reintegration experiences of veterans with PTSD and their significant others. Am J Orthopsychiatry 2017;87:149-56.

8. Paley B, Lester P, Mogil C. Family systems and ecological perspectives on the impact of deployment on military families. Clin Child Fam Psychol Rev 2013;16:245-65.

9. Murphy RA, Kasprow WJ, Rosenheck RA. Predictors of children's involvement in parents' treatment among homeless veterans in community residential care. Psychiatr Serv 2005;56:1147-9.

10. Hamilton AB, Poza I, Hines V, Washington DL. Barriers to psychosocial services among homeless women veterans. J Soc Work Pract Addict 2012; $12: 52-68$.

11. Bassuk EL, Buckner JC, Perloff JN, Bassuk SS. Prevalence of mental health and substance use disorders among homeless and low-income housed mothers. Am J Psychiatry 1998;155:1561-4.

12. Buckner JC, Bassuk EL, Weinreb LF, Brooks MG. Homelessness and its relation to the mental health and behavior of low-income school-age children. Dev Psychol 1999;35:246-57.

13. Zima BT, Wells KB, Benjamin B, Duan N. Mental health problems among homeless mothers: Relationship to service use and child mental health problems. Arch Gen Psychiatry 1996;53:332-8.

14. Haber MG, Toro PA. Homelessness among families, children, and adolescents: an ecological-developmental perspective. Clin Child Fam Psychol Rev 2004;7:123-64.

15. Silverbush M, Kuhn J, Southcott L. FY 2017 Annual Report Supportive Services for Veteran Families (SSVF). US Department of Veterans Affairs; 2017. Available at: https://www.va.gov/homeless/ssvf/docs/ SSVF_FY2017_AnnualReport_508.pdf. Accessed June 26, 2020.

16. U.S. Department of Veterans Affairs. US Department of Housing and Urban Development-VA Supportive Housing (HUD-VASH) Program. Available at: https://www.va.gov/homeless/hud-vash.asp. Accessed June 29, 2020.

17. United States Interagency Council on Homelessness. Opening Doors: Federal Strategic Plan to Prevent and End Homelessness. United States Interagency Council on Homelessness; 2010.

18. Los Angeles Homeless Services Authority. 2019 Greater Los Angeles Homeless Count - Data Summary; 2019.

19. Shinn M, Brown SR, Gubits D. Can housing and service interventions reduce family separations for families who experience homelessness? Am J Community Psychol 2017;60:79-90.

20. Paperwork Reduction Act, 44 U.S.C. 3501 (1995). Available at: https://www.reginfo.gov/public/reginfo/ pra.pdf. Accessed October 29, 2020.

21. Namey E, Guest G, McKenna K, Chen M. Evaluating bang for the buck: A cost-effectiveness comparison between individual interviews and focus groups based on thematic saturation levels. Am J Eval 2016;37:425-40.

22. Bronfenbrenner U. Ecological Systems Theory. In: Vasta R, ed. Six Theories of Child Development: Revised Formulations and Current Issues. London: Jessica Kinsley Publishers; 1992:187-249.

23. Patton MQ. Enhancing the quality and credibility of qualitative analysis. Health Serv Res 1999;34:1189208.

24. ATLAS.ti. Version 8. Scientific Software Development; 1998. Available at: https://atlasti.com/. Accessed June 26, 2020.

25. Glaser BG, Strauss AL. Discovery of Grounded Theory: Strategies for Qualitative Research. Routledge; 2017.

26. Rice A, Kim JYC, Nguyen C, Liu WM, Fall K, Galligan P. Perceptions of masculinity and fatherhood among men experiencing homelessness. Psychiatr Serv 2017;14(2):257.

27. Silverbush M, Kuhn J, Thompson R. FY 2018 Annual Report Supportive Services for Veteran Families (SSVF); 2018. Accessed June 29, 2020.

28. Meis LA, Barry RA, Kehle SM, Erbes CR, Polusny MA. Relationship adjustment, PTSD symptoms, and treatment utilization among coupled National Guard soldiers deployed to Iraq. J Fam Psychol 2010;24:560-7.

29. McNulty PAF. Reported stressors and health care needs of active duty Navy personnel during three phases of deployment in support of the war in Iraq. Mil Med 2005;170:530-5.

30. Evans L, Cowlishaw S, Forbes D, Parslow R, Lewis $\mathrm{V}$. Longitudinal analyses of family functioning in veterans and their partners across treatment. J Consult Clin Psychol 2010;78:611-22.

31. Schinka JA, Curtiss G, Leventhal K, Bossarte RM, Lapcevic W, Casey R. Predictors of mortality in older homeless veterans. J Gerontol B Psychol Sci Soc Sci 2017;72:1103-9.

32. Schinka JA, Leventhal KC, Lapcevic WA, Casey R. Mortality and cause of death in younger homeless veterans. Public Health Rep 2018;133: 177-81.

33. Tsai J, Cao X. Association between suicide attempts and homelessness in a population-based sample of US veterans and non-veterans. $\mathrm{J}$ Epidemiol Community Health 2019;73:346-52.

34. Kuo DZ, Houtrow AJ, Arango P, Kuhlthau KA, Simmons JM, Neff JM. Family-centered care: 
current applications and future directions in pediatric health care. Matern Child Health J 2012;16:297-305.

35. Lester P, Mogil C, Saltzman W, et al. Families overcoming under stress: implementing family-centered prevention for military families facing wartime deployments and combat operational stress. Mil Med 2011;176:19-25.

36. Makin-Byrd K, Gifford E, McCutcheon S, Glynn S. Family and couples treatment for newly returning veterans. Prof Psychol Res Pr 2011;42:47-55.

37. Sherman MD. Updates and five-year evaluation of the SAFE program: A family psychoeducational program for serious mental illness. Community Ment Health J 2006;42:213-9.

38. Ridings LE, Moreland AD, Petty KH. Implementing trauma-focused CBT for children of veterans in the VA: providing comprehensive services to veterans and their families. Psychol Serv 2019;16:75-84.

39. Medicine I. O. Returning Home from Iraq and Afghanistan: Assessment of Readjustment Needs of Veterans, Service Members, and Their Families. National Academies Press; 2013.

40. Garg A, Jack B, Zuckerman B. Addressing the social determinants of health within the patient-centered medical home: Lessons from pediatrics. JAMA 2013;309:2001-2.

41. Chung EK, Siegel BS, Garg A, et al. Screening for social determinants of health among children and families living in poverty: A guide for clinicians. Curr Probl Pediatr Adolesc Health Care 2016;46:135-53.

42. Hughes LS, Likumahuwa-Ackman S. Acting on social determinants of health: A primer for family physicians. Am Fam Physician 2017;95:695-6.
43. Garg A, Toy S, Tripodis Y, Silverstein M, Freeman E. Addressing social determinants of health at well child care visits: a cluster RCT. Pediatrics 2015; 135:e296-2888.

44. O’Toole TP, Johnson EE, Aiello R, Kane V, Pape L. Tailoring care to vulnerable populations by incorporating social determinants of health: the veterans health administration's "Homeless Patient Aligned Care Team" program. Prev Chronic Dis 2016;13:150567.

45. Chatterjee A, So M, Dunleavy S, Oken E. Quality health care for homeless families: achieving the AAP recommendations for care of homeless children and youth. J Health Care Poor Underserved 2017;28:1376-92.

46. Aykanian A, Larkin H. Health care innovations for homeless families: Emerging opportunities under Medicaid and the Affordable Care Act. J Child Poverty 2015;21:59-68.

47. Burt MR, Wilkins C, Mauch D. Medicaid and permanent supportive housing for chronically homeless individuals: Literature synthesis and environmental scan. Office of the Assistant Secretary for Planning and Evaluation; 2011.

48. California Housing Partnership. Los Angeles County Renters in Crisis: A Call for Action. California Housing Partnership; 2017.

49. National Low Income Housing Coalition. Out of Reach: The High Cost of Housing. National Low Income Housing Coalition; 2017. https://nlihc.org/ sites/default/files/oor/OOR_2017.pdf.

50. Khouri A. L.A. City Council moves to outlaw discrimination against Section 8 tenants. Los Angeles Times. April 17, 2019. Available at: https://www.latimes.com/ business/la-fi-section-8-ordinance-20190417-story.html. Accessed June 29, 2020. 


\section{Appendix}

\section{Interview Guide}

I. We know there are many difficulties and challenges when living without a place of your own as a mother and father. We would like to learn more about what it is like being a mother [or father] in these circumstances.

a. Can you tell me what it is like to be a mother [or father] when you are homeless?

II. Experiences with Different Life Sectors:

Now, we would like to hear more about the many different areas of your life that were potentially affected by being without housing. For this part of the interview, we will use the help of this guide, or "sector wheel" to help learn about your experiences and to try to not leave anything out. We would like to discuss all the topics here on the wheel, but we want you to be in charge of the process. So feel free to start with a topic. Please think of your experiences while you were living without a place of your own, and during your current situation.
For each topic:

a. Tell me about [area] and your experiences/ concerns about this; when you were staying without a place of your own and during your current situation

b. Tell me what did not work for you and your family?

i. What was it about the services or programs that did not work?

c. What worked for you and your family?

i. What was it about the services or programs that worked?

d. Did you use VA services to help you with problems in this area? Why or why not?

\section{Recommendations}

Given all that we have talked about today, what can be done to improve services for homeless veteran parents and their families?

a. What do you recommend?

b. What could be better? 